\title{
Leadership Behaviors of Superintendent/Principals in Small, Rural School Districts in Texas
}

\author{
Maria T. Canales \\ Kingsville Independent School District \\ Carmen Tejeda-Delgado \\ Texas A\&M University-Kingsville
}

John R. Slate

Sam Houston State University

In this study, 206 teachers, 35 school board presidents, and 37 superintendents/principals $(n=278)$ were surveyed regarding their views of effective leadership behaviors demonstrated by school leaders with dual role responsibilities through serving as both a school principal and as a superintendent in small rural school districts. Data were collected through use of the Leadership Behavior Description Questionnaire Form XII and the Leadership Behavior Description Questionnaire Form XII Self. Of the 12 leadership domains assessed through use of this measure, statistically significant differences were yielded on 6 of the 12 leadership areas: Representation; Demand Reconciliation; Tolerance of Uncertainty; Persuasiveness; Initiation of Structure; and Role Assumption. Superintendents/principals reported lower scores in these areas than did teachers and/or school board presidents. Implications of these findings are discussed.

\section{Introduction}

Since the mid-1700s, the backbone of American education has been rural education. At that time, of the country's 212,000 one-room schools, $1 / 2$ of American school children were enrolled. Today, nearly $1 / 3$ of American school children attend public schools in rural communities, of which they constitute $43 \%$ of all American public schools (United States Department of Education, 2003). Since their creation, small rural school districts have been primarily a one-person operation. Historically, a small rural school district hired a schoolmaster or teacher to serve multiple roles such as teacher, principal, nurse, cook, and custodian (Hilton, 1949). Today, many rural school districts continue this practice through the superintendent/principal position. Because small school systems lack the number of positions available in larger systems, a single administrator is often given several coordinated responsibilities which would normally warrant a separate position in a larger school district (Wylie \& Clark, 1991). Such administrators truly wear "many hats." They are subject to what Katz and Kahn (1978) termed "role ambiguity," wherein uncertainty about what a job should include coupled with an unwieldy range of role expectations leads to low job satisfaction and high tension (p. 190).

Small rural school districts across America are confronted with many issues. Concerns over inadequate funding and increased state and federal mandates, such as No Child Left Behind, continue to add to an already full administrative agenda. Therefore, superintendent/principals in small rural schools face the daily challenge of meeting these demands and providing effective leadership.
In the State of Texas, 44 small rural school districts operate with one district administrator, the superintendent/principal. Superintendent/principals of small rural school districts in the State of Texas, as well as in other states, are expected to be effective leaders while performing their two roles. They must complete the same number of reports and meet the same accountability standards as superintendents of larger districts while performing the dual responsibilities of both superintendent and principal. Regardless of the size of a school district, superintendent/principals are still required to complete the same reports and adhere to the accountability requirements imposed by the Texas Education Agency, the state legislature, and the United States Department of Education. Because small school districts lack the number of positions available in larger districts, a single administrator often is given several "coordinated" responsibilities which warrant a separate position in a larger school district (Wylie \& Clark, 1991). Consequently, superintendent/principals truly wear "many hats" and face an enormous task of effectively performing the multiple roles and responsibilities of the dual role position. Multiple roles and responsibilities of the dual position may impede the educational leader's ability to lead effectively (Lochry, 1998).

These superintendent/ principals need to learn how to effectively lead with the dual responsibilities that are inherent to both positions.

\section{Purpose of the Study}

The purpose of the study was to identify effective leadership behaviors exhibited by superintendent/principals 
as perceived by superintendent/principals, by teachers, and school board presidents. Similarities and differences in these perceptions were investigated.

\section{Research Questions}

1. What effective leadership behaviors are exhibited by the superintendent/principal?

2. What effective leadership behaviors exhibited by superintendent/principals are identified by teachers?

3. What effective leadership behaviors exhibited by superintendent/principals are identified by school board presidents?

4. What are the differences in the effective leadership behaviors identified on the between superintendent/principals, teachers and school board presidents?

\section{Methods and Procedures}

\section{Participants}

The target population for the study included all the superintendent/principals in small rural school districts in Texas serving as sole administrators, the school board presidents, and the teachers of these same districts. Participants in the study were identified using information from the Texas Education Agency's ASK Ted (directory) database, the Texas Association of School Board's database, and the Education Service Center Regions I through XX databases. Respondents for the study were 206 teachers, 35 school board presidents, and 37 superintendent/principals ( $n$ $=278)$. Of the superintendent/principal respondents, $60 \%$ ( $n$ $=22$ ) were between the ages of 51-60+ with $87 \%$ of those same respondents being Anglo $(n=32)$. Of the superintendent/principals who responded to the survey, $46 \%$ $(n=17)$ had 10-20 total years of experience with $78 \%$ being male $(n=28)$. Of the school board presidents who responded, $49 \%(n=17)$ were between the ages of 41-50, with $71 \%$ of those same respondents being Anglo $(n=25)$. Of the school board presidents who responded to the survey, $51 \%(n=18)$ had $6-10$ years of experience with $77 \%$ of those same respondents being male $(n=27)$.

\section{Instrumentation}

Survey instruments that were utilized in this study were the Leadership Behavior Description Questionnaire Form XII (LBDQ-Form XII) and the Leadership Behavior Description Questionnaire Form XII Self (LBDQ-Form XII Self). The LBDQ has been utilized in a variety of research situations including, military, industrial, and educational (Stogdill, 1974). This instrument was used in research projects by 85 known faculty members or graduate students in 62 different universities during the 1962 and 1963 years alone (Stogdill, 1974).

Today, the LBDQ-Form XII and the LBDQ-Form XII Self contain 100 items each that fall into 12 subscales. The subscales are: 1) Representation, 2) Demand Reconciliation, 3) Tolerance of Uncertainty, 4) Persuasiveness, 5) Initiation of Structure, 6) Tolerance of Freedom, 7) Role Assumption, 8) Consideration, 9) Production Emphasis, 10) Predictive Accuracy, 11) Integration, and 12) Superior Orientation. The LBDQ-Form XII and the LBDQ-Form XII Self were selected for the study based on their alignment with the review of literature and the study's research questions. Data were collected utilizing these questionnaires to identify the exhibited leadership behaviors of superintendent/principals.

\section{Reliability}

To ensure reliability of the instrument, the LBDQForm XII was pilot tested with a sample of practicing teachers and school board presidents from small districts in Regions I, II, and III who were randomly selected from the Education Service Center, Regions I, II, and III databases and were not a part of the actual study. A similar pilot study and procedures were followed using the LBDQ-Form XII Self with practicing principals and superintendents randomly selected from small districts in Region I, II, and III. An item analysis was conducted to obtain Cronbach's coefficient alpha, the most frequently used estimate of internal consistency (Trochim, 2002). Reliability analysis was conducted with two separate groups. The first group analyzed measured responses from superintendents and principals $(n=18)$. The procedure output had an overall raw alpha of .67 (rounded from .6661), which is acceptable considering that $.60+$ is the acceptable value for reliability according to social sciences (Hatcher, 1994). A second analysis was conducted to measure responses from teachers ( $n=17)$. Again, the output raw alpha was .95 , which is considered to be a high degree of reliability.

\section{Procedures}

First, participants of the study, superintendent/ principals, teachers, and school board presidents of small rural school districts in Texas were identified through the Texas Education Agency's ASK Ted Directory, Texas Association of School Boards, and the Education Service Center Regions I through XX databases. Next, the LBDQForm XII and the LBDQ-Form XII Self were mailed out to all the identified participants who were quested to complete the questionnaire in paper form or online. A turn-around time period of two weeks was observed before sending out a second request to participants who had not responded. Finally, the senior researcher made telephone, e-mail, and/or regular mail contact with non-respondents within two weeks from the second written request. Each district/participant was assigned a number to keep track of respondents and 
non-respondents. Confidentiality was guaranteed by having anonymous surveys.

Data were collected from three groups, the superintendent/principals, teachers and school board presidents. Teachers and school board presidents completed the same questionnaire (LBDQ-Form XII), whereas superintendent/principals completed a different version of the same questionnaire (LBDQ-Form XII Self). Demographic information and the questionnaire responses were checked for accuracy prior to the statistical analyses and then entered into the Statistical Package for the Social Sciences software (SPSS, version 11.0, Norusis, 2000).

\section{Results}

To satisfy the primary assumptions for the use of parametric tests such as ANOVA, all data were examined prior to analysis for normality and homogeneity of variance. Data results indicated that the assurances were met.

Research Question One: What effective leadership behaviors are exhibited by the superintendent/principal? For this sample, 37 participants responded to the survey. Scores ranging from 5 (Always) to 1 (Never) were used to determine prioritization of leadership behaviors as identified by superintendent/principals. Results of descriptive statistics showed that Tolerance of Freedom $(M=40.67, S D=3.184)$, Representation $(M=40.22, S D=4.366)$ and Consideration $(M=39.72, S D=3.460)$ were ranked most prevalent by superintendent/principals participating in the study. Group comparisons of means and standard deviations for each subscale are displayed in Table 1.

Research Question Two: What effective leadership behaviors exhibited by superintendent/ principals are identified by teachers (see above)? Data in Table 1 represents 206 respondents. Scores ranging from 5 (Always) to 1 (Never) were used to determine prioritization of leadership behaviors as identified by teachers. Results of descriptive statistics showed that Representation $(M=$ $43.58, S D=5.286)$, Tolerance of Freedom $(M=41.70, \mathrm{SD}=$ 5.956), and Role Assumption $(M=41.66, S D=5.645)$ were ranked most prevalent by teachers participating in the study.

Research Question Three: What effective leadership behaviors exhibited by superintendent/ principals are identified by school board presidents? As indicated in Table 1, data represented 35 study participants. Results of descriptive statistics showed that Representation $(M=$ 42.86, $S D=5.600)$, Consideration $(M=41.97, S D=5.788)$, and Demand Reconciliation $(M=41.77, S D=6.189)$ were ranked most prevalent by school board presidents participating in the study.

Research Question Four: What are the differences in the effective leadership behaviors identified by superintendent/principals, teachers and school board presidents? Oneway Univariate Analyses of Variance (ANOVA) procedures were conducted to evaluate the relationship between position and mean responses on the 12 subscales of the LBDQ. The independent variable, the factor "position," included three levels: superintendent/principals, teachers, and school board presidents. Dependent variables were the mean responses for each of the 12 subscales.

The ANOVA for Subscale 1 Representation was statistically significant, $F(2,275)=6.54, p<.01$. The strength of the relationship between position and mean Representation score, as assessed by $\eta^{2}$, was moderate, with the position factor accounting for $5 \%$ of the variance in the dependent variable.

Follow-up tests were conducted to evaluate pairwise differences among the means. Based on the Levene's Test of Equality of Error Variances $(p=.352)$, the Bonferroni test was used. A statistically significant difference in the means was present between superintendent/principals and teachers. The mean response on the Subscale 1 Representation for teachers was 3.36 greater than that of superintendent/principals. Therefore, teachers reported higher frequencies of Representation behavior of the leader than did the individual superintendent/principals themselves. Representation is defined as the leader's ability to speak and act as the representative of the group. Teachers believed their superintendent/principals were the true representative leader of the district. Conversely, superintendent/principals appear to rate themselves lower in Representation, indicating less confidence in their ability to be the representative leader for the group.

The ANOVA for Subscale 2 Demand Reconciliation was statistically significant, $F(2,275)=5.15, p<.01$. The strength of the relationship between position and mean representation score, as assessed by $\eta^{2}$, was moderate, with the position factor accounting for $4 \%$ of the variance in the dependent variable. Follow-up tests were conducted to evaluate pairwise differences among the means. Based on the Levene's Test of Equality of Error Variances $(p=.007)$, the Dunnett's C test was used. Statistically significant differences were found in the means between superintendent/principals and teachers and between superintendent/principals and school board presidents. The mean responses on Subscale 2 Demand Reconciliation for teachers and school board presidents respectively were 3.87 and 4.47 greater than that of superintendent/principals. Consequently, teachers and school board presidents reported higher frequencies of Demand Reconciliation behavior than did the individual superintendent/principals themselves. Demand Reconciliation refers to the leader's ability to reconcile conflicting demand and his/her ability to reduce disorder to system. Teachers and school board presidents believed their superintendent/principals were skilled at reconciling conflicting demands and maintaining order in the district. Superintendent/principals, on the other hand, appeared less confident in their ability to mange conflicting demands and maintain organizational order. 
Table 1

Descriptive Statistics for Leadership Behaviors as Identified by School Board Presidents, Teachers, and Superintendent/Principals

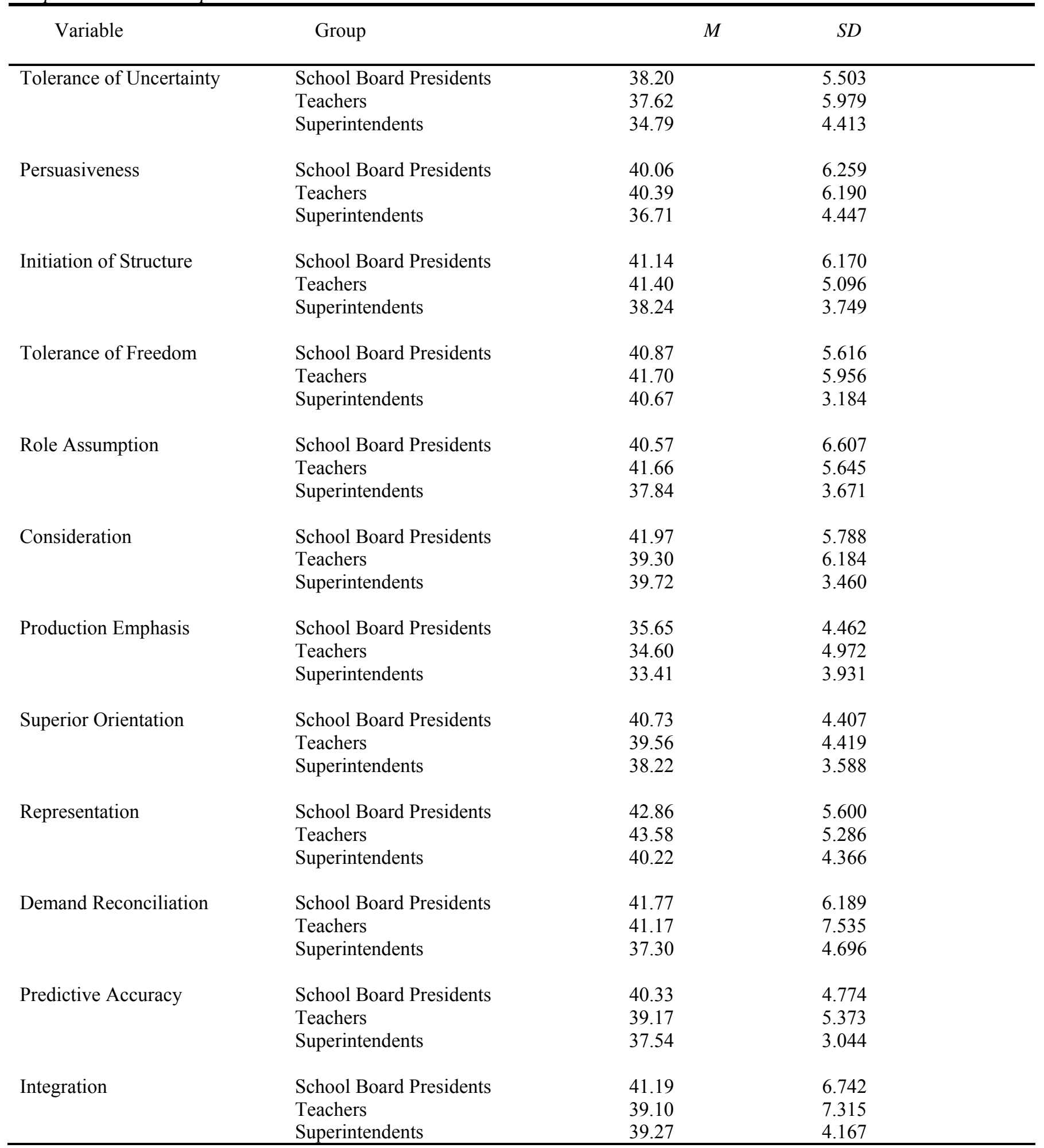


The ANOVA for Subscale 3 Tolerance of Uncertainty was also statistically significant, $F(2,275)=4.28, p<.01$. The strength of the relationship between position and mean "Tolerance of Uncertainty" score, as assessed by $\eta^{2}$, was moderate, with the position factor accounting for $3 \%$ of the variance in the dependent variable. Follow-up tests were conducted to evaluate pairwise differences among the means. Based on the Levene's Test of Equality of Error Variances $(p=$. 067), the Bonferroni test was used. Statistically significant differences were found between superintendent/principals and teachers and between superintendent/principals and school board presidents. The mean responses on Subscale 3 Tolerance of Uncertainty for teachers and school board presidents respectively were 2.83 and 3.41 greater than that of superintendent/principals. Therefore, as found in the previous summary, both teachers and school board presidents reported higher frequencies of Tolerance of Uncertainty behavior of the leader than did the superintendent/principals themselves. Tolerance of Uncertainty is defined as the leader's ability to tolerate uncertainty and postponement without anxiety or upset. Teachers and school board presidents believed their superintendent/principals were highly skilled in their ability to tolerate uncertainty and postponement with out becoming anxious or upset. Conversely, superintendent/principals did not report a high confidence level in their ability to tolerate uncertainty in the organization.

The ANOVA for Subscale 4 Persuasiveness was also statistically significant, $F(2,275)=5.92, p<.01$. The strength of the relationship between position and mean Persuasiveness score, as assessed by $\eta^{2}$, was moderate, with the position factor accounting for $4 \%$ of the variance in the dependent variable. Follow-up tests were conducted to evaluate pairwise differences among the means. Based on the Levene's Test of Equality of Error Variances $(p=.145)$, the Bonferroni test was used. A statistically significant difference was yielded between superintendent/principals and teachers. The mean response on the Subscale 4 Persuasiveness for teachers was 3.68 greater than that of superintendent/principals. Teachers reported higher frequencies of Persuasiveness behavior of the leader than did the individual superintendent/principals themselves. Persuasiveness means the leader's ability to use persuasion and argument effectively. Teachers believed their superintendent/ principals were highly skilled in their effective use of persuasion and argument. As in the previous subscales, superintendent/principals reported less confidence in their ability to use persuasion and argument effectively.

The ANOVA for Subscale 5 Initiation of Structure was statistically significant, $F(2,275)=6.10, p<.01$. The strength of the relationship between position and mean "Initiation of Structure" score, as assessed by $\eta^{2}$, was moderate, with the position factor accounting for $4 \%$ of the variance in the dependent variable. Follow-up tests were conducted to evaluate pairwise differences among the means. Based on the Levene's Test of Equality of Error Variances $(p=.016)$, the Dunnett's C test was used. A statistically significant difference was present between superintendent/principals and teachers. The mean response on the Subscale 5 Initiation of Structure for teachers was 3.17 greater than that of superintendent/principals. As noted in prior summaries, teachers reported higher frequencies of Initiation of Structure behavior of the leader than the individual superintendent/principals themselves. Initiation of Structure refers to the leader clearly defining his/her own role and letting followers know what is expected. Teachers believed their superintendent/ principals adequately defined their role as leader and consistently let followers know what is expected. Again, superintendent/principals did not report a high confidence level in their ability to clearly define their role and explain their expectations to their followers. This finding may perhaps be due to the role ambiguity associated with the dual role position of superintendent/principal.

The ANOVA for Subscale 7 Role Assumption was also statistically significant, $F(2,275)=7.53, p<.001$. The strength of the relationship between position and mean "Role Assumption" score, as assessed by $\eta^{2}$, was moderate, with the position factor accounting for 5\% of the variance in the dependent variable. Follow-up tests were conducted to evaluate pairwise differences among the means. Based on the Levene's Test of Equality of Error Variances $(p=.085)$, the Bonferroni test was used. A statistically significant difference was yielded between superintendent/principals and teachers. The mean response on the Subscale 7 Role Assumption for teachers was 3.82 greater than that of superintendent/principals. Teachers reported higher frequencies of Role Assumption behavior of the leader than did the superintendent/principals themselves. Role Assumption is defined as the leader's ability to actively exercise the leadership role rather than surrendering leadership to others. Teachers believed their superintendent/principals actively exercised the leadership role and seldom surrendered their leadership to others. Conversely, superintendent/principals reported less confidence in their ability to consistently retain their leadership role.

The ANOVAs for the subscales of Tolerance of Freedom, Consideration, Production Emphasis, Predictive Accuracy, Integration, and Superior Orientation were not statistically significant, $p s>.05$. The three groups of respondents did not differ statistically in their views in these leadership areas.

\section{Discussion}

Results of descriptive statistics listed the top three leadership behaviors as identified on the LBDQ-Form XII and LBDQ-Form XII Self by superintendent/principals, teachers, and school board presidents. All three groups identified Representation as one of the most prevalent leadership behaviors among superintendent/principals. Tolerance of Freedom and Consideration were also 
identified by two of the groups as being most prevalent. These results appear to emphasize the importance of the superintendent/principals' need to be the symbolic leader for the district.

Statistically significant differences were found between 6 of the 12 LBDQ subscales. Two groups, superintendent/principals and teachers, revealed significant differences in their perceptions of Representation, Persuasion, Initiation of Structure, and Role Assumption. Additionally, all three groups, superintendent/principals, teachers, and school board presidents, indicated statistically significant differences in their views of Demand Reconciliation and Tolerance of Uncertainty. Superintendent/principals consistently rated themselves lower than teachers and school board presidents rated them. These differences appear to be a result of the dual role administrators being overly critical of themselves in their self-evaluations on the LBDQ-Form XII Self. These results may also be tied to the multiplicity of duties and responsibilities inherent in the position and the leader's lack of confidence in effectively accomplishing them.

Representation is the leader's ability to speak and act as the representative of the group. A difference of opinion existed between superintendent/principals and teachers in relation to their perceptions of leader representation. Teachers perceived their leaders as being the representative of the group more often than superintendent/ principals saw themselves as representing the group. In addition, perceptions did not differ on Representation between school board presidents and teachers and between school board presidents and superintendent/principals.

Demand Reconciliation is defined as the leader's ability to reconcile conflicting demands and reduce disorder to system. Differing opinions existed between the perceptions of superintendent/principals and teachers and between superintendent/ principals and school board presidents in relation to Demand Reconciliation. Teachers and school board presidents appeared to rate their leaders higher in their ability to deal with conflicting demands than did superintendent/principal themselves. Similarly, differing perceptions were not present between teachers and school board presidents in relation to Demand Reconciliation. Consequently, superintendent/principals appear to be more critical of themselves, rating their conflict resolution skills lower than teachers and school board presidents rated them.

Tolerance of Uncertainty pertains to the leader being able to tolerate uncertainty and postponement without anxiety or upset. Differing views were again present between superintendent/principals and teachers and between superintendent/principals and school board presidents in relation to Tolerance of Uncertainty. Teachers and school board presidents perceived superintendent/principals as being highly tolerant of uncertainty in their dual positions. In contrast, superintendent/principals rated themselves lower in their ability to tolerate uncertainty. Thus, superintendent/principals may evaluate themselves more critically than their superiors and subordinates.

Persuasiveness is related to the leader's use of persuasion and argument effectively and their exhibiting of strong convictions. Again, superintendents/principals differed from teachers in regard to this leadership characteristic. Teachers rated dual role administrators higher in their ability to persuade followers than superintendent/principals rated themselves. Superintendent/principals appear to evaluate themselves harder than teachers and school board presidents. Differing opinions were not present between superintendent/principals and school board presidents and between teachers and school board presidents in relation to Persuasiveness.

Initiation of Structure relates to the leader's ability to clearly define his/her own role and let followers know what is expected. A difference was again present between the perceptions of superintendents/principals and teachers. As in the previous summary, teachers perceived superintendent/principals to be higher in structure than they perceived themselves. Differences were not found between superintendent/principals and school board presidents and between teachers and school board presidents.

Tolerance of Freedom refers to the leader allowing the followers scope for initiative, decision, and action. With no differences present, these data support Stogdill (1974) who suggested that leaders who tolerate high degrees of member freedom of action tend to be described high in consideration. Role Assumption deals with the leader actively exercising the leadership role rather than surrendering leadership to others. Superintendent/principals perceived themselves as often surrendering their leadership role to others, whereas teachers perceived them to be leaders who consistently retain their authority. These differing opinions align with the more critical self-evaluations of superintendent/principals in the previous summaries of leadership behaviors.

Subsequently, no statistically significant differences were found between the three groups in the six subscales of Tolerance of Freedom, Consideration, Production Emphasis, Predictive Accuracy, Integration, and Superior Orientation. Superintendent/principals, teachers, and school board presidents reported consistent frequencies of these leadership behaviors. The similar ratings of these subscales between the three groups appear to indicate a general agreement that promoting collaboration, being empathetic, emphasizing productivity, promoting a team atmosphere, and maintaining cordial relations with superiors are important leadership behaviors.

\section{Conclusions}

Results of the study have implications for improving administrator preparation programs. The dual position of superintendent/principal is a multi-faceted role which requires a variety of leadership skills and behaviors. Conclusions of the study are presented according to the dual 
job responsibilities, effective leadership behaviors, occupational stressors, and stress coping strategies associated with the superintendent/principal position.

Analysis revealed that both superintendent/principals and school board presidents agreed on the top three leadership behaviors required for leadership success. Both groups ranked Tolerance of Freedom, allowing follower's initiative, decision-making, and action as the most important leadership behavior associated with the dual administrative position. The second leadership behavior prioritized by superintendent/principals and school board presidents was Representation and Consideration was ranked third. On the other hand, teachers rated Representation ahead of Tolerance of Freedom, as the most effective leadership behavior of the superintendent/principal and Role Assumption, as the third most important. Teachers indicated that the leader speaking and acting as the representative of the group was the most important leadership behavior. Leadership behavior, as indicated by the literature, can be narrowed to two relatively independent behavior categories: initiating structure and consideration (Hersey, Blanchard, \& Johnson, 2001). Superintendent/principals, teachers, and school board presidents listed Consideration as the most effective leadership behavior of the dual administrative position. According to Stogdill (1974), leaders who tolerate high degrees of member freedom of action tend to be described high in consideration.

\section{Recommendations}

As the literature indicates, superintendent/principals wear many hats, thus making effective leadership a challenge. The following recommendations are based upon the findings and conclusions of the study:

(1) Superintendent/principals need to prioritize their job responsibilities in an effort to ensure completion of the most critical issues inherent in the dual position.

(2) Dual administrators should participate in time management training. This training could assist them in prioritizing their duties and responsibilities.

(3) School districts should budget resources for a separate principal or assistant principal whenever feasible to alleviate the occupational stress dual administrators often face.

(4) Superintendent/principals would benefit from attending stress management workshops. This attendance would assist dual administrators in learning how to effectively deal with the daily pressures of being the "go to person" for everything in the district.

(5) Dual role administrators would benefit from participating in self-evaluation or self-awareness programs in an effort to assist them in identifying their strengths and building on them.

(6) A network of small school superintendent/principals and mentors should be established to provide peer support.

\section{Recommendations for Further Study}

As a result of the study, several recommendations for further study have emerged. First, a similar study to this one needs to be conducted on a broader, national level to determine the generalizability of these findings. Second, it is recommended that a study be performed focusing on the dual responsibilities of superintendent/principals and the relationship of these responsibilities with student achievement. Finally, a case study, on the different leadership and management styles of a practicing male and female superintendent/principal, would contribute to the extant literature.

\section{References}

Hatcher, L. (1994). A step-by step approach to using the $S A S{ }^{\circledR}$ system for factor analysis and structural equation modeling. Cary, NC: SAS Institute.

Hersey, P., Blanchard, K. H., \& Johnson, D. E. (2001). Management of organizational behavior: Leading human resources, $\left(8^{\text {th }}\right.$ ed.). Upper Saddle River, NJ: Prentice Hall.

Hilton, E. (1949). Rural school management. New York: American Book Co.

Katz, D., \& Kahn, R. L. (1978). The social psychology of organizations, $\left(2^{\text {nd }}\right.$ ed.). New York: John Wiley.

Norusis, M. J. (2000). SPSS guide to data analysis. Upper Saddle River, NJ: Prentice Hall.

Stogdill, R. M. (1974). Handbook of leadership: A survey of the literature. New York: The Free Press.

Texas Association of School Boards. (2001). Board policy manual. Austin, TX: TASB.

Texas Association of School Boards. (2004). Membership Division. Barbara Schlosser, Membership Director, Austin, TX.

Texas Education Agency. (2003). Data element names and definitions (All TEA information collections). Available:

http://ww.tea.state.tx.us/clearinghouse/de/winners.cgi?c oomand $=$ win_results\&letter $=\mathrm{E} \& d b f i l e=\mathrm{de} . t \mathrm{txt}$

Trochim, W. M. (2002). The research methods knowledge base. $2^{\text {nd }}$ Edition. Retrieved June 18, 2004 from http://trochim.human.cornell.edu/kb/index.htm

U.S. Department of Agriculture. (2003). Rural development. Retrieved November 2, 2003, from http://www.rurdev.usda.gov/

U. S. Department of Education. (2003). Rural education. Retrieved September 3, 2003, from http://www.ed.gov./inits/rural/index.html

Wylie, V. L., \& Clark, E. H. (1991). Administration in small schools: Smart heads for new hats. The Rural Educator, 13(1), 24-27. 